Objective Low birth weight infants (LBW) are at increased risk of cognitive and behavioral problems and at risk of iron deficiency (ID) which is associated with impaired neurodevelopment. We hypothesized that iron supplementation of LBW infants would improve cognitive scores and reduce behavioral problems.

Patients and methods: In a randomized controlled trial, 285 marginally LBW (2000-2500g) infants received 0 , 1, or $2 \mathrm{mg} / \mathrm{kg} /$ day of iron supplements from six weeks to six months of age. At 3.5 years of age these infants and 95 normal birth weight controls were assessed with a psychometric test (WIIPSI-III) and a questionnaire of behavioral problems (CBCL).

Results There were no significant differences in IQ between the LBW-groups, nor compared to controls. Mean (SD) full-scale IO was 105.2 (14.5), 104.2 (14.7), and 104.5 (12.7) in the placebo, $1 \mathrm{mg}$, and 2 mg-group respectively ( $p=0.924)$. The prevalence of children with CBCL-scores above the US subclinical cut-off was $12.7 \%, 2.9 \%$, $2.7 \%$, and $3.2 \%$ in the placebo, $1 \mathrm{mg}, 2 \mathrm{mg}$, and control-group respectively. Relative risks ( $95 \% \mathrm{CI}$ ) for behavioral problems vs. controls were 4.01 (1.13-14.29) in the placebo-group. In a logistic regression model, adjusted for confounders, the odds ratio (95\% CI) for CBCL score above US subclinical cut-off in placebo-treated children was 4.5 (1.3-15.8) compared to iron supplemented children $(p=0.019)$.

Conclusions Early iron supplementation of marginally LBW infants does not affect cognitive functions at 3.5 years of age but significantly reduces the prevalence of behavioral problems. The study suggests a causal relation between infant ID and later behavioral problems.

\section{A RETROSPECTIVE COHORT STUDY TO ASSESS THE ASSOCIATION BETWEEN OUTDOOR AIR QUALITY AND LOW BIRTH WEIGHT}

doi:10.1136/archdischild-2012-302724.0989

${ }^{1} \mathrm{MC}$ Ribeiro, ${ }^{2} \mathrm{E}$ Llop, ${ }^{3} \mathrm{C}$ Branquinho, ${ }^{4} \mathrm{CM}$ Dias, ${ }^{5} \mathrm{~A}$ Tavares, ${ }^{6} \mathrm{~F}$ Santos, ${ }^{1} \mathrm{~A}$ Soares, ${ }^{1} M J$ Pereira. ${ }^{1}$ Cerena/DECivil, Instituto Superior Técnico; Universidade Técnica de Lisboa, Lisbon, Portugal; 'Biologia Vegetal-Botánica, Universitat de Barcelona, Barcelona, Spain; ${ }^{3}$ Ecologia e Biologia Vegetal, Universidade de Lisboa; Faculdade de Ciencias; ${ }^{4}$ Epidemiologia, Instituto Nacional de Saúde Ricardo Jorge; ${ }^{5}$ Administração Regional de Saúde Lisboa e Vale do Tejo, Direção Geral de Saúde, Lisbon; ${ }^{\circ}$ Administração Regional de Saúde Alentejo, Direção Geral de Saúde, Sines, Portugal

Introduction Low birth weight (LBW) is defined by the World Health Organization as weight at birth of less than 2500 g. Epidemiological observations suggest that LBW contributes to a range of poor infant's health outcomes. Other studies suggest that an increase of outdoor air pollution levels may increase the incidence of LBW. This article presents results from a semi-ecological analysis of association between outdoor air quality and LBW in a cohort of mothers participating in Gestão Integrada Saúde e Ambiente (GISA) project, in Alentejo Litoral region (Portugal).

Materials Individual data on birth weight, residence, demographic, social and clinical covariates were collected by questionnaire from mothers ( $n=1393$ ) participating on GISA project. Air quality data was collected with a lichen diversity biomonitoring program measured at spatiality distributed sampling sites $(n=84)$.

Methods Lichen biomonitoring was used to derive a continuous metric of outdoor air quality exposure. Geostatistical simulation was applied to lichen diversity data to derive equally probable maps of air quality with different exposure scenarios for each pregnant, to gain insight into exposure distribution and exposure uncertainty. Generalized linear models were used to predict the odds of LBW.

Results Factors found significantly $(p<0.05)$ associated to LBW: smoking habits, prenatal surveillance, body mass index, intrauterine growth, weight gain during pregnancy, previous LBW. Air quality was not associated to LBW (odds, 1.001; confidence interval 95\%, 0.998-1.006).
Conclusions Air quality was not associated to LBW. Factors found to be significantly associated with LBW are in line with scientific knowledge.

\section{ETHNIC DIFFERENCES IN NEONATAL BODY COMPOSITION AND THE IMPACT OF PARENTAL SIZE. A POPULATION- BASED COHORT STUDY}

doi:10.1136/archdischild-2012-302724.0990

${ }^{1,2,3} \mathrm{~L}$ Sletner, ${ }^{1,3 \mathrm{~B}}$ Nakstad, ${ }^{2} \mathrm{~S}$ Vangen, ${ }^{3,4} \mathrm{~K}$ Mørkrid, ${ }^{3,4} \mathrm{~K}$ Birkeland, ${ }^{5} \mathrm{AK}$ Jenum. ${ }^{1} \mathrm{Child}$ and Adolescents Medicine, Akershus University Hospital, Lørenskog; ${ }^{2}$ Norwegian Resource Centre for Women's Health, Oslo University Hospital; ${ }^{3}$ nstitute of Clinical Medicine, University of Oslo; ${ }^{4} \mathrm{Dep}$. of Endocrinology, Oslo University Hospital; ${ }^{5} / n s t i t u t e$ of Health and Society, University of Oslo, Oslo, Norway

Background and Aim Neonatal size, and especially a relative "thinness", is associated with future risk of obesity and type 2 diabetes. The aim was to explore ethnic differences in neonatal body composition in a multi-ethnic population, and associations with parental anthropometrics and parity.

Methods A population-based cohort study of healthy pregnant women living in Oslo, Norway. Maternal data were collected in early pregnancy and neonatal weight, length, circumferences and skin folds after birth. Individual z-scores were calculated (stratified by gender and gestational age) with Western Europeans (WE) as reference. A general linear model was used to assess associations with parental anthropometry and parity. Crude and adjusted mean z-scores for neonates with origin from low- and middle income countries (LAMIC), with WE as reference, is presented.

Results 511 healthy, term neonates were included. LAMIC parents $(n=282)$ were shorter than WE $(n=229)$, had similar BMI but more maternal subcutaneous fat. Among the LAMIC neonates abdominal circumference differed the most from WE (mean z-score: $-0.57 \mathrm{SD}$ (95\% CI:-0.69 to -0.44)) Neonatal skin folds were also smaller in the immigrant group $(-0.29$ ( -0.40 to -0.17$)$. Length, however, was not significantly smaller $(-0.21(-0.35$ to -0.07$))$. The observed ethnic differences were reduced when adjusting for parental body composition, but abdominal circumference remained significantly smaller $(-0.37$ ( -0.53 to -0.21$)$ ).

Conclusions There were marked differences in neonatal body composition between neonates born by ethnic WE women and women with ethnic origin from LAMIC countries. Abdominal circumference was still smaller after adjustment for parental body composition.

\section{NONINVASIVE VENTILATION IN CHILDREN, CAN WE PREDICT ITS FAILURE?}

doi:10.1136/archdischild-2012-302724.0991

P García Soler, MJ Vicente Martín, A Morales Martínez, JM González Gómez, G Milano Manso. Pediatric Intensive Care Unit, Hospital Regional Universitario Materno Infantil Carlos Haya, Málaga, Spain

Background and Aims Noninvasive ventilation (NIV) constitutes an alternative treatment for pediatric acute respiratory failure. However, tracheal intubation should not be delayed when considered necessary. Our main objective is to identify success/failure prognostic signs of NIV and determination of NIV characteristics. Methods Noncontrolled, observational study in a PICU in a university hospital. All cases of NIV from June 2010 and March 2012 were included. Failure of NIV was defined as the requirement of endotracheal intubation at any time. The major characteristics of patients who were intubated were compared with the characteristics of those who were not after a trial of NIV. Predictive factors for failure of NIV were analysed by multivariate analysis.

Results 126 cases were included (60.3\% males), mean age $25.3 \pm 40.5$ months and mean weight $11 \pm 13 \mathrm{~kg}$. There was $57.9 \%$ of type II 